\title{
PIPERACEAE DO PARQUE NACIONAL DA SERRA DA CANASTRA, MINAS GERAIS, BRASIL
}

\author{
MICHELINE CARVALHO-SILVA* \& ELSIE FRANKLIN GUIMARÃES** \\ *Jardim B otânico de B rasília, SM D B Quadra Conjunto 12 s.n., 71680-120 - B rasília, DF, B rasil. \\ **J ardim B otânico do Rio de J aneiro, Rua Pacheco L eão 915, 22460-030 - Rio de J aneiro, RJ, B rasil.
}

\begin{abstract}
A bstract - (Piperaceae of the Serra da Canastra N ational Park, M inas Gerais, B razil). This work presents the Piperaceae species of Parque Nacional da Serra da Canastra, M inas Gerais, based on specimens deposited in BHCB, HUFU, R, RB, SP and SPF herbaria. There are 16 species in the region, with two new records for $\mathrm{M}$ inas Gerais, and one first record for B razil. Descriptions, illustrations, keys to the genera and species, as well as comments on the geographical distribution and habitats are presented.
\end{abstract}

\begin{abstract}
R esumo - (Piperaceae do Parque Nacional da Serra da Canastra, M inas Gerais, B rasil). 0 trabalho apresenta as espécies de Piperaceae que ocorrem no Parque N acional da Serra da Canastra, M inas Gerais baseado em espécimes depositados nos herbários B HCB , HUFU, R, RB, SP e SPF. Foram registradas 16 espécies, sendo duas novas ocorrências para o estado de M inas G erais e uma nova espécie para o Brasil. São apresentadas descrições da família, dos gêneros e espécies, chaves de identificação, ilustrações e comentários sobre distribuição geográfica e habitat.
\end{abstract}

Key words: Piperaceae, Piper, Peperomia, Serra da Canastra National Park.

\section{Introdução}

As Piperaceae possuem cerca de 3000 espécies com distribuição pantropical. No B rasil ocorre cerca de 500 táxons e são reconhecidos três gêneros: Piper L., Peperomia Ruiz \& Pav. e M anekia Trel. (Tebbs 1989).

A família vem sendo estudada desde L innaeus (1753) que descreveu 17 espécies das quais nove são reconhecidas para o B rasil. Dentre os principais estudiosos da família pode-se destacar Miquel (1943-1944, 1952), De Candolle (1869) e Trelease \& Yuncker (1950). Para o B rasil, os principais trabal hos publicados foram o de T.G. Yuncker "The Piperaceae of Brazil" (1972, 1973, 1974) que reúne seus estudos de 50 anos com a família. A obra é a mais abrangente e foi publicada em três partes, onde 0 autor revisa as Piperaceae para 0 B rasil, descreve e fotografa 457 espécies.

$M$ ais recentemente, trabalhos como floras locais (Guimarães 1994a, 1994b, 1997, C arval ho-Silva \& Caval canti 2002, Guimarães \& Giordano 2004, Guimarães et al. 2007), descrições de espécies novas (Guimarães et al. 1977, Guimarães \& Carvalho-Silva 2005) e sinonímias (Guimarães \& Costa 1980) foram realizadas para esta família.

Este trabal ho apresenta o levantamento das Piperaceae no Parque Nacional da Serra da Canastra, M inas Gerais e faz parte dos estudos da família no B rasil.

\section{M aterial e M étodos}

Área de estudo: 0 Parque Nacional da Serra da Canastra (PNSC) situa-se no sudoeste do estado de M inas Gerais entre as coordenadas $20^{\circ} 00^{\prime}-20^{\circ} 30^{\prime} \mathrm{S}$ e $46^{\circ} 15^{\prime}-47^{\circ} 00^{\prime} \mathrm{W}$ e insere-se no bioma Cerrado. 0 parque compreende uma área de 71.525 hectares, nos municípios de São Roque de M inas, Sacramento e Delfinópolis e tem como principais tipos de vegetação os campos limpo, campos sujo, cerrado sensu stricto, campos rupestres e matas, sendo que as espécies de Piperaceae encontram-se apenas nos três últimos tipos de vegetações.

O btenção e análise de material: Para a realização do trabalho foram analisados exemplares de Piperaceae dos herbários BHCB, HUFU, R, RB, SP e SPF. Durante o período de preparação do trabal ho foi realizada uma excursão para 0 Parque Nacional da Serra da Canastra, onde os ambientes e as espécies foram observados e fotografados.

\section{Resultados}

Foram registradas 16 espécies de Piperaceae sendo oito para o gênero Piper e oito para Peperomia. Dentre as espécies estudadas, apenas Peperomia oreophilla Henschen e P. subrubrispica C.DC. foram observadas nos campos rupestres, as demais ocorrem em matas, preferindo locais sombreados e 
úmidos. Peperomia dahlstedtii C.DC. e Piper glabratum Kunth ainda não haviam sido citados para o estado de M inas Gerais, mas ambas espécies são encontradas freqüentemente em outras regiões do Cerrado. Piper viminifolium Trel., espécie com poucos exemplares registrados no parque, é encontrada também nos cerrados de M inas G erais e G oiás. $O$ levantamento ainda apresenta uma nova espécie para o Parque $\mathrm{N}$ acional da Serra da Canastra: Piper canastrense E.F. Guim \& M . Carvalho-Silva, semelhante a Piper viminifolium, mas que tem como principal diferença a presença de tricomas estrelados na lâmina foliar, o que é pouco freqüentes nas Piperaceae.

\section{TRATAMENTO TAXONÔMICO \\ Piperaceae C. A gardh}

Ervas epífitas, rupícolas ou terrestres, subarbustos, arbustos, arvoretas ou árvores; ramos suculentos, raro lenho- sos; profilos ausentes ou presentes, persistentes ou caducos; tricomas simples, raro estrelados. Folhas geralmente alternas, ocasionalmente opostas ou verticiladas, pecioladas; pecíolos simples ou alados; lâminas simples, inteiras, base simétrica ou assimétrica. Espigas ou racemos, simples ou compostos, raramente dispostos em umbelas, terminais, axilares, ou opostos às folhas; raquis carnosas, raro ramificadas, foveoladas ou não, lisas, estriadas, verrucosas ou fimbriadas; brácteas presentes ou ausentes; uma bráctea floral por flor. Flores bissexuadas, aperiantadas; estames 2-4, anteras bitecas, deiscência rimosa; ovário súpero, unilocular, uniovular, placentação basal, estilete presente ou ausente, estigma 1-4 lobado, papiloso, óvulo ortótropo. Fruto do tipo drupa.

Chave para os gêneros

1. Ervas terrestres, epífitas ou rupículas. Estames 2, estigma 1. Peperomia 1'. Subarbustos, arbustos ou arvoretas. Estames 3-4, estigmas 3 2. Piper

\section{Peperomia Ruiz \& Pav.}

Ervas terrestres, rupícolas ou epífitas, eretas, escandentes, cespitosas ou estoloníferas; ramos suculentos. Fol has alternas, verticiladas ou opostas, geralmente suculentas, glabras a pubescentes, base simétrica; nervação eucamptódroma, hifódroma, campilódroma ou acródroma. Espigas solitárias ou em pares, terminais, axilares, ou opostas às folhas; brácteas presentes ou ausentes; raquis foveoladas ou não, glabras ou com tricomas; bráctea floral peltada, glabra. Flores com simetria bilateral; estames 2; estilete presente ou ausente; es- tigma 1. D rupas rostradas ou não, providas de pseudocúpula ou não, papilosas, lisas, glândulosas ou pilosas.

0 gênero Peperomia está representado por cerca de 170 espécies no B rasil. 0 estado de M inas Gerais apresenta ca. de 135 espécies e oito destas encontram-se no Parque Nacional da Serra da Canastra. As Peperomia são caracterizadas vegetativamente pelo hábito herbáceo e fol has geralmente suculentas. $M$ uitas espécies são cultivadas como ornamentais, entre elas $P$. obtusifolia A. Dietr. e P. argyreia (M iq.) E. M orr. sendo encontradas, não raro, em vasos de casas e em jardins públicos.

\section{Chave para as espécies}

1. Folhas alternas.

2. Folhas ovadas a depresso-ovadas, às vezes levemente elípticas, base truncada a obtusa, raro levemente cordada.

B ráctea presente 1.8. P. urocarpa

2'. Fol has elípticas, base decurrente. B ráctea ausente

1.6. P. subrubricaulis

$1^{\prime}$. Fol has opostas ou verticiladas.

3. Fol has opostas

4. B ráctea ausente

1.6. P.subrubricaulis

4'. B ráctea presente.

5. Fol has orbiculares, raro elípticas ou transversal mente elípticas, até 5,5 mm compr., hirtelas a tomentoso-vilosas

5'.Fol has elípticas, acima de $30 \mathrm{~mm}$ compr., glabras

1.2. P. dahlstedtii

3 '. Fol has verticiladas.

6. Raquis pubescente

1.4. P. oreophylla

$6^{\prime}$. Raquis glabra. 
7. Folhas com ápice emarginado 1.5. P. quadrifolia

7'. Folhas com ápice redondo a obtuso ou agudo, não emarginado.

8. Ramos fortemente tomentosos, folhas 3-verticiladas

1.7. P. subrubrispica

8'. Ramos glabros, folhas (3) 4-6 verticiladas

1.3. P. Ioxensis 1820.

1.1. Peperomia circinnata Link, B ot. Jahrb. 1 (3): 64.

Fig. 1 g-h.

Ervas epífitas, estoloníferas, prostradas, ramos hirtelos. Fol has opostas, suculentas, hirtelas a tomentoso-vilosas, concolores, verde-claras, acródromas; pecíolos 1-2 mm, tomentosos; lâminas 3-5,5 mm compr., 3-5,5 mm larg., orbiculares, raro elípticas ou transversalmente elípticas; ápice obtuso, base obtusa, margem levemente ciliada; nervuras 3, inconspícuas. Espigas 50-60 mm compr., $2 \mathrm{~mm}$ larg., verdes, solitárias, terminais ou axilares, eretas; pedúnculos 10-60 $\mathrm{mm}$; brácteas 2, 1,5-2,5 mm compr., opostas na metade do pedúnculo, sésseis, eretas, lineares, carenadas, ápice obtuso, margem ciliada; raquis foveoladas, glabras. D rupas $0,5-0,8$ mm compr., globosas a levemente elípticas, glabras, desprovidas de pseudocúpula, ápice levemente dilatado, rugoso, marrom, sem prolongamento lateral, estilete ausente, estigma apical, fortemente papiloso.

Material examinado: Delfinópolis, Paraíso Selvagem, trilha para "Desertinho", 20²6' 04"S, 46³8'73"W, 24.X.2003 (fl), R.A. Pacheco et al. 692 (HUFU).

Peperomia circinnata distribui-se nas Índias Ocidentais e A mérica do Sul (Yuncker 1974) e no B rasil a espécie ocorre em matas de galeria em todo o território nacional. A espécie é facilmente reconhecida devido às fol has opostas e muito pequenas em relação às outras espécies que ocorrem na região.

1.2. Peperomia dahlstedtii C.DC., Candollea 1: 305. 1923.

Fig. 1 k-l.

Ervas rupícolas ou terrestres, estoloníferas, ramificadas; ramos ascendentes, quadrangulares quando material seco, fortemente estriados, glabros. Folhas opostas, suculentas, glabras, concolores, verde-claras, acródromas; pecíolos 0,5$0,8 \mathrm{~cm}$, canaliculados, hirtel os; lâminas $30-50 \mathrm{~mm}$ compr., 15-25 mm larg., elípticas; ápice obtuso, base aguda a decurrente; nervuras 3, creme, impressas na face adaxial, proeminentes na face abaxial. Espigas 70-85 mm compr., $2 \mathrm{~mm}$ larg., creme a verdes, solitárias ou em pares, terminais, eretas; pedúncul os 2,0-2,3 mm, hirtelos; brácteas 2, ca. $0,3 \mathrm{~cm}$ compr., opostas na metade do pedúnculo, triangulares; raquis fissuradas, foveoladas, glabras. Drupas $0,75-1 \mathrm{~mm}$ compr., ovais, glabras, providas de pseudocúpula abaixo do meio da drupa, estigma apical.

$M$ aterial examinado: Delfinópolis, Trilha para cachoeira do Triangulo, Fazenda Zé A ntunes, 20²6'30"S, 4646'02"W, 06.XII.2002 (fl),
J.N. Nakajima et al. 3391 (HUFU); trilha Escalada das Pedras, Fazenda ZéA ntunes, $20^{\circ} 26^{\prime} 04^{\prime \prime} \mathrm{S}, 46^{\circ} 38^{\prime} 72^{\prime \prime} \mathrm{W}, 10.11 \mathrm{l} .2003$ (fr), R.L. Volpi et al. 516 (HU FU); Trilha Casinha Branca, Fazenda ZéA ntunes, 20²6'04"S, 46³8'72"W, 11.IV.2002 (fl), R.A. Pacheco et al. 164 (HUFU); Paraíso Perdido, Fazenda Zé A ntunes, $20^{\circ} 26^{\prime} 30^{\prime \prime} S, 46^{\circ} 46^{\prime} 02^{\prime \prime} \mathrm{W}, 23 . X .2003$ (fl), J.N. Nakajima et al. 3599 (HUFU); São Roque de Minas, morro próximo à Sede administrativa, Parque N acional Serra da Canastra, 19.Il.1997 (fr), R. Romero et al. 3837 (HUFU).

A espécie ocorre nos estados do Ceará (Guimarães \& Giordano 2004), A mazonas, Pará, M ato Grosso e Paraná e esta sendo citada pela primeira vez para o estado de M inas Gerais. Foi observada ocorrendo em altitudes que variam de 841-996 m. A floração e a frutificação ocorrem durante todo 0 ano. P. dahlstedtii apresenta fol has opostas, bastante suculentas com três nervuras conspícuas. A espécie diferencia-se das ocorrentes no Parque N acional da Serra da Canastra devido à ocorrência de brácteas pedunculares associada a presença de pseudocúpula no fruto.

1.3. Peperomia loxensis K unth in H.B.K., N ov. gen. sp. pl. 1: 70. 1815.

Fig. $1 \mathrm{c}-\mathrm{d}$

Ervas epífitas ou terrestres, estoloníferas, ramificadas; ramos ascendentes $15-40 \mathrm{~cm}$ alt., glabros. Folhas (3) 4-6 verticiladas, suculentas, geralmente côncavas, concolores, verde-claras, hifódromas; pecíolos ca. 2 mm, glabros; lâminas 8-21 mm compr., 5-12 mm larg., elípticas a raro obovais, glabras com glândulas castanhas; ápice obtuso a agudo, às vezes com tricomas curtos na face abaxial, base aguda a cuneada, margem lisa; nervuras inconspícuas. Espigas 20$24 \mathrm{~mm}$ compr., $2 \mathrm{~mm}$ larg., verdes, na frutificação 20-65 mm compr., 2-3 mm larg., solitárias, terminais, ou raro axilares, eretas; pedúncul os 7-10 mm, glabros; brácteas ausente; raquis fissuradas, glabras. D rupas $0,75-1 \mathrm{~mm}$ compr., ovais a oblongas, glabras ou com curtos tricomas, castanho-claras, com pseudocúpula abaixo do meio da drupa, estilete persistente, $0,3 \mathrm{~mm}$, estigma apical.

Material examinado: São Roque de M inas, Cachoeira dos Rolinhos, Parque Nacional Serra da Canastra, 21.VIII.1997 (fl), R. Romero et al. 4464 (CEN, HUFU); Córrego Quilombo, 16.VII.1995 (fl), R. Romero et al. 2436 (CEN, HUFU); M ata do Córrego do Quilombo, 26.IX.1995 (estéril), R. Romero et al. 2801 (CEN, HUFU); Nascente do Rio São Francisco, 16.X.1994 (fl), R. Romero et al. 1291 (HUFU). Delfinópolis, Paraíso Perdido, cachoeira Triangulo, Fazenda Zé A ntunes, 20²6 30"S, $46^{\circ} 46^{\prime} 02^{\prime \prime}$, 23.X.2003 (fr), J. N. Nakajima et al. 3600 (HUFU).

Peperomia loxensis ocorre na Venezuela, Colombia, Equador e no B rasil nos estados de M inas Gerais, Rio de Ja- 
neiro, São Paulo, Santa Catarina (Trelease \& Yuncker 1950, Yuncker 1974), Goiás e no Distrito Federal (Carvalho-Silva \& Cavalcanti 2002). A espécie foi observada em matas de galeria e campos úmidos a altitudes de 1000-1600 m. Peperomia loxensis apresenta-se como erva estolonífera ramificada e tem como característica marcante as drupas ovaloblongas com uma pequena capa que reveste a base do fruto, formando uma estrutura semel hante a uma cúpula e o estilete persistente. A espécie pode ser confundida com P. galioides devido às fol has verticiladas, mas são diferenciadas primeiramente pelos frutos que em $P$. galioides são arredondados sem pseudocúpula.

1.4. Peperomia oreophilla Henschen, Nova A cta Soc. Sci. U psal. III. 8:28. 1873.

Fig. 1 o-p.

Ervas rupículas, eretas; ramos ascendentes, estriados, 15-30 cm alt., hirsutos, tricomas longos, 1-2 mm, patentes. Folhas 4-7-verticiladas, suculentas, acródromas; pecíolos 1-2 mm, hirsutos; lâminas 0,7-1,2 mm compr., 0,5-1,0 mm larg., orbiculares a levemente elípticas, cobertas por glândulas negras, face adaxial glabra, face abaxial hirtela a vilosa; ápice obtuso, base obtusa, margem ciliada; nervuras 3, inconspícuas. Espigas 20-25 mm compr., $3 \mathrm{~mm}$ larg., creme a esverdeadas, solitárias, terminais, eretas; pedúncul os $10 \mathrm{~mm}$ compr., vilosos, brácteas ausente; raquis foveoladas, pubescentes. Drupas $0,7 \mathrm{~mm}$ compr., ovais a oblongas, glabras, castanho-claras, providas de pseudocúpula abaixo do meio da drupa, estigma apical.

Material examinado: São Roque de Minas, morro atrás do Centro de Visitantes, Parque N acional Serra da Canastra, 25.IX.1995 (fl), J.N.Nakajima et al. 1351 (HUFU).

A espécie tem sido observada apenas para os estados de $M$ inas Gerais e São Paulo. Esta é facilmente distinta das outras espécies ocorrentes no Parque Nacional da Serra da Canastra devido à presença de tricomas na raquis, enquanto todas as outras espécies possuem a raquis glabra.

1.5. Peperomia quadrifolia (L.). H.B.K., N ov. gen. \& sp. 1:69. 1815.

Fig. 1 a-b.

Ervas epífitas, eretas; ramos ascendentes, $15 \mathrm{~cm}$ alt., glabros. Folhas 4-5 verticiladas, hifódromas; pecíolos 1-3 mm, glabros; lâminas 10-15 mm compr., 6-10 mm larg., obovadas, glândulas castanhas, glabras; ápice emarginado; base aguda, levemente decurrente; margem levemente revoluta; nervuras central conspícua. Espigas 25-50 mm compr., $2 \mathrm{~mm}$ larg., solitárias, terminais, eretas; pedúnculos 10-15 mm, glabros; brácteas ausentes; raquis foveoladas, glabras. Drupas 0,5 mm compr., ovais, glabras castanhoclaras, providas de pseudocúpula abaixo do meio da drupa, estigma apical.
Material examinado: São Roque de Minas, Estrada para o retiro das Pedras, Parque Nacional da Serra da Canastra, 14.V.1995 (fl, fr), R.Romero et al. 2310 (CEN, HUFU).

Peperomia quadrifolia é uma planta glabra com folhas verticiladas e é freqüentemente reconhecida devido às fol has apresentarem 0 ápice emarginado. Ocorre nas Índias Ocidentais, A mérica do Sul e Central. No B rasil tem sido citada para os estados de M inas Gerais, Rio de J aneiro e São Paulo.

1.6. Peperomia subrubricaulis C.DC., Bull. Herb. B oiss. II. 7:141. 1907.

Fig. 1 e-f.

Ervas terrestres; ramos eretos, 0,25-0,40 cm alt., hirtelos a glabrescentes. Fol has opostas e alternas na base, suculentas, acródromas; pecíolos 5-7 mm, tomentosos; lâminas 30-50 mm compr., 15-22 mm larg., elípticas, face adaxial tomentosa a glabrescente, face abaxial tomentosa, glândulas negras esparsas; ápice agudo, ciliado, base decurrente, margem levemente revoluta; lâminas dos ramos basais 20-35 mm compr., 15-22 mm larg., ápice obtuso; nervuras 3, conspícuas. Espigas $50 \mathrm{~mm}$ compr., $2 \mathrm{~mm}$ larg., verdes, solitárias, terminais, eretas; pedúnculos $13 \mathrm{~mm}$; brácteas ausentes; raquis foveoladas, glabras. Drupas 0,5-0,8 mm compr., globosas, glabras, desprovidas de pseudocúpula, estigma apical.

Material examinado: São Roque de Minas, Parque Nacional Serra da Canastra, Cachoeira dos Rolinhos "Ilhota", 23.11 .1997 (fl, fr), R. Romero et al. 3986 (CEN, HUFU); Nascente do Córrego Bárbaro, 24.VIII.1997 (estéril), J.N. Nakajima et al. 2795 (CEN, HUFU).

Peperomia subrubricaulis tem sido registrada apenas para o estado de M inas Gerais. A espécie foi coletada a última vez por Heringer em 1947, desde então os registros têm sido apenas para o Parque Nacional da Serra da Canastra. A espécie possui as folhas do ápice opostas, as da base al ternas e três nervuras do tipo acródromas, mas não apresenta bráctea peduncular e nem pseudocúpula no fruto.

1.7. Peperomia subrubrispica C.DC., Bull. Herb. B oiss. II. 7: 142. 1907.

Fig. $1 \mathrm{i}-\mathrm{j}$.

Ervas rupícolas, eretas a estoloníferas, ramificadas na base ou próximo a esta; ramos ascendentes ou pendentes, 8-25 cm, tomentosos. Folhas 3-verticiladas, discolores, acródromas; pecíolos 1-2 mm, fortemente tomentosos; lâminas 5-10-(15) mm compr., 4-7(12) mm larg., elípticas a amploelípticas, ambas as faces tomentosas negropontuadas; ápice obtuso, base obtusa, margem ciliada; nervuras 3, inconspícuas. Espigas 15-60 mm compr., 2-3 mm larg, solitárias, terminais; pedúnculos 8-15 mm, poucos tricomas; bráctea ausente; raquis foveoladas, glabras. Drupas $0,5 \mathrm{~mm}$ compr., elípticas ou globosas, desprovidas de pseudocúpula, ápice levemente oblíquo, glanduloso, estigma subapical. 
Material examinado: São Roque de M inas, PARNA Serra da Canastra, Estrada para cachoeira da Casca D'A nta, afloramentos rochosos, 23.XI.1995 (fl), J.N. Nakajima et al. 1612 (CEN, HU FU); Topo da Colina próximo a sede administrativa, 21.II.1994 (fr), J.N. Nakajima \& R. Romero 168 (CEN, HUFU); Curral das Pedras, 15.XII.1998 (fr), M.A. Farinaccio 242 (HUFU); M orro próximo a sede administrativa, 15.VII.1995 (fl, fr), R. Romero et al. 2356 (CEN, HU FU); M orro próximo a sede administrativa, 17.III.1995 (fl, fr), R. Romero et al. 1945 (CEN, HUFU); M orro Próximo a Sede A dministrativa, Parque Nacional Serra da Canastra, 19.II.1997 (fr), R. Romero et al. 3837 (CEN, HUFU).

Peperomia subrubrispica ocorre no sudeste do país e tem sido observada no Parque Nacional da Serra da Canastra apenas nos campos rupestres. A espécie apresenta grande pilosidade nos ramos assim como $\mathrm{P}$. oreophylla, mas esta se distingue por apresentar fol has 4-7 verticiladas e a raquis totalmente pilosa, enquanto P. subrubrispica apresenta folhas 3 -verticiladas e raquis glabra.

1.8. Peperomia urocarpa Fisch. \& M ey., Index sem. hort. petrop. 4: 42. 1837.

Fig. 1 m-n.

Ervas terrestres, epífitas ou rupícolas, prostradas, ramificadas; ramos $15-25 \mathrm{~cm}$ alt., pendentes, tomentosos a glabrescentes nas partes mais vel has. Folhas alternas, discolores, campilódromas; pecíolos 10-18 (50) mm compr., levemente tomentosos; lâminas 28-45 x 24-48 mm, ovais a depresso-ovais, as vezes leve elípticas; ápice obtuso, levemente mucronado, base truncada a obtusa ou raro levemente cordada; margem plana, ciliada; face adaxial hirtela a levemente tomentosa, glândulas castanhas a enegrecidas em ambas as faces, face abaxial com raros tricomas esparsos; nervuras (3)-5, conspícuas, na face adaxial, tomentosas. Espigas 23-45 mm compr., 1,5-3 mm larg., solitárias, opostas às folhas; pedúnculos 20-40 $(6,8) \mathrm{mm}$ compr., tomentosos; bráctea 4-5 mm compr., solitária, no meio do pedúnculo, linear, carenada, ápice agudo a obtuso com tricomas eretos na ponta, face adaxial tomentosa, face abaxial glabra; raquis levemente estriadas, foveoladas, glabras. Drupas ca. 1,5 mm alt., oblongas a levemente elípticas, rostradas, cobertas por glândulas amarelas, douradas a avermel hadas, desprovida de pseudocúpula, ápice com prolongamento lateral ca. 0,3 mm compr., estigma sublateral, castanho-alaranjadas, pericarpo fino, livre da semente.

M aterial examinado: Sacramento, Parque Nacional da Serra da Canastra, estrada São Roque de M inas-Sacramento, a $41 \mathrm{~km}$ da Portaria de São Roque de M inas, 7.XI.2002 (fl), A.F. Pontes et al. 538 (SPF); São Roque de Minas, nascente do córrego do Bárbaro, 24.VIII.1997 (fl), J.N. Nakajima et al. 2765 (CEN).

Peperomia urocarpa foi registrada para as Índias Ocidentais, Venezuela, Colômbia Equador e Brasil (Steyermark 1984) nas regiões N ordeste, Centro-O este, Sul e Sudeste (Yuncker 1974). A espécie apresenta as folhas al ternas com nervuras campilódromas e um longo prolongamento no fruto com estigma sublateral o que diferencia facilmente a espécie.

\section{Piper L .}

Subarbustos, arbustos a arvoretas; profilo único, às vezes oculto no pecíolo, geralmente caduco. Fol has alternas, glabras a pubescentes, base simétrica ou assimétrica; nervação eucamptódroma, campilódroma, acródroma, broquidódroma ou actinódroma; pecíolo simples, às vezes alado. Espigas ou racemos, solitários, opostos às fol has ou raramente dispostos em umbelas na axila das fol has; brácteas pedunculares raramente presentes. Flores sésseis ou pediceladas; estames 3-4; estilete presente ou ausente; estigma 3 lobado. Drupas glabras a densamente pubescentes.

0 gênero Piper está representado nos estados de M inas Gerais por 45 táxons, sendo que oito ocorrem no Parque Nacional da Serra da Canastra. Os representantes de Piper são subarbustos a arvoretas encontrados principalmente em matas de galeria, mas podem ocorrer em cerrados, veredas e matas secas.

\section{Chave para as espécies}

1. Presença de tricomas estrelados na face abaxial da lâmina

2.3. P. canastrense

$1^{\prime}$. Tricomas simples.

2. Fol has cobertas por glândulas castanhas.

3. Espigas curtas $25-36 \mathrm{~mm}$, pêndulas 2.2. P. caldense

3'. Espigas longas 70-130 mm, eretas 2.5. P. glabratum

$2^{\prime}$. Fol has desprovidas de glândulas castanhas.

4. Fol has com base da lâmina assimétrica.

5. Pecíolo alado, ala em todo o pecíolo com prolongamento 3-7 mm em direção à lâmina foliar ...... 2.1. P . arboreum 5'. Pecíolo desprovido de alas.

6. Face adaxial da lâmina foliar pubescente a tomentosa, lâminas 17-25 compr., 10-15 larg., nervuras de 5-7 de cada lado 2.7. P. tectoniifolium

6' .Face adaxial da lâmina foliar híspida a estrigosa, lâminas $9-18 \mathrm{~cm}$ compr., 4-8 cm larg., nervuras 4-5 de cada lado 

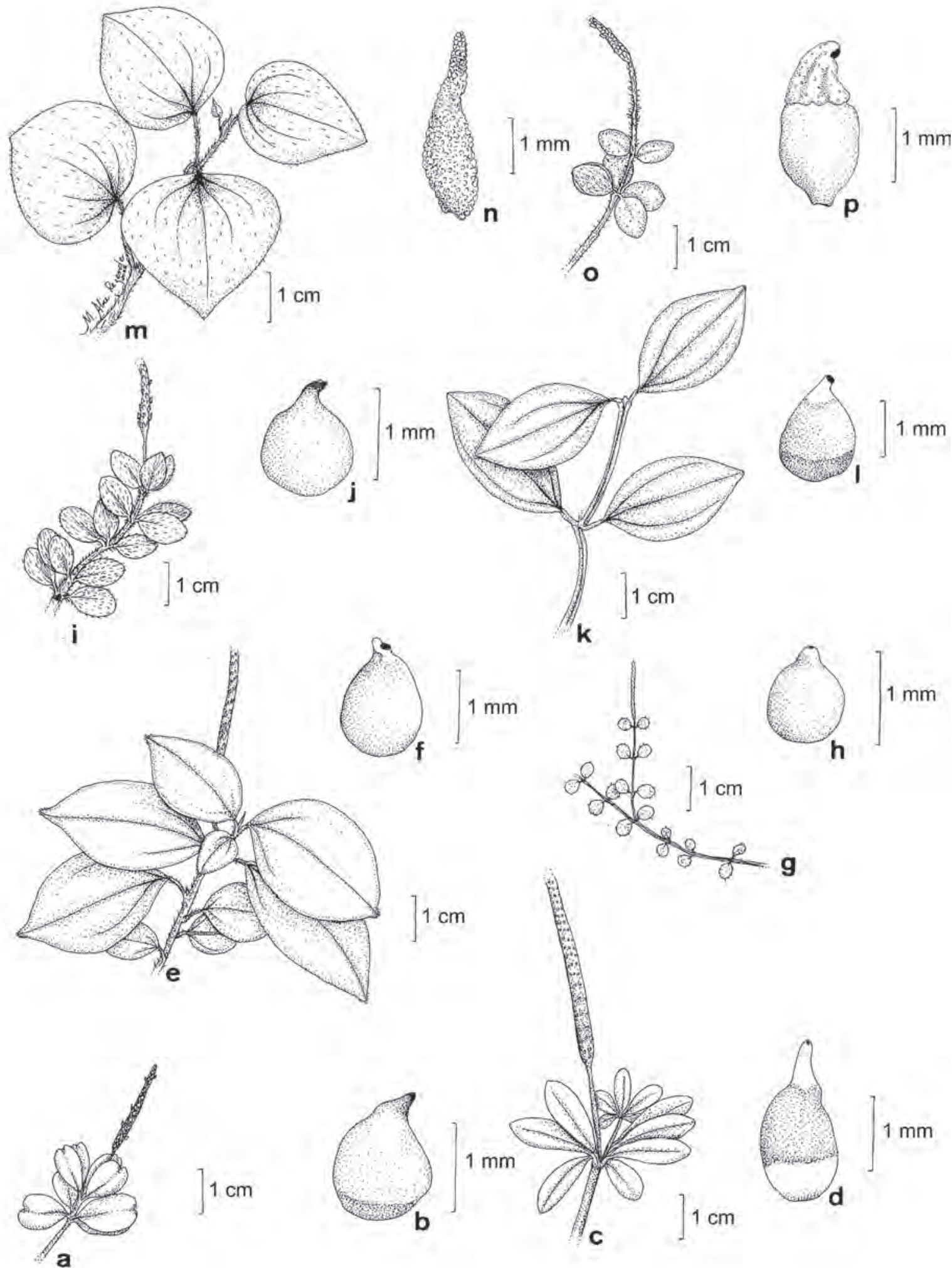

Fig. 1: a-b. Peperomia quadrifolia (L.) H.B.K., a - hábito, b-detalhe do fruto. c-d. Peperomia loxensis H.B.K., c-hábito, d-detal he do fruto. e-f. Peperomia subrirubricaulis C.DC., e-hábito, f-detalhe do fruto. g-h. Peperomia circinnata Link, g- hábito, h- detalhe do fruto. i-j- Peperomia subrubrispica C.DC., i- hábito, j-detalhe do fruto. k-I. Peperomia dahlstedtii C.DC. k- hábito, I- detalhe do fruto. m-n. Peperomia urocarpa Fischer \& M eyer, m- hábito, n-detalhe do fruto. o-p. Peperomia oreophilla Henschen, o-hábito, p-detal he do fruto. 
4'. Fol has com base da lâmina simétrica.

7. Fruto com estilete persistente, laminas foliares $5-13 \mathrm{~cm}$ larg., bráctea floral ciliada 2.4. P. crassinervium

7'. Fruto sem estilete persistente, lâminas foliares 1,5-3,5 cm larg., bráctea floral glabra 2.8. P. viminifolium

2.1. Piper arboreum Aubl. subsp. arboreum, Hist. PI. Guiane 1: 23. 1775.

Fig. $2 \mathrm{~g}$-h.

A rbustos a arvoretas $3 \mathrm{~m}$ alt; ramos glabros a puberulentos. Profilos caducos. Folhas, cartáceas, eucamptódromas; pecíolos 2-3 mm, alados, ala em todo o pecíolo com prolongamento 3-7 mm em direção à lâmina foliar; lâminas 14-25 cm compr., 3,5-10 cm larg., I anceoladas, obl ongo-lanceoladas; face adaxial glabra; ápice agudo a atenuado, base assimétrica, obtusa a cordada, diferença 10-30 mm entre os lados; face abaxial glabra a pubescente; nervuras ca. 9 de cada lado, 2-3 saindo do lobo maior, glabras a pubescentes. Espigas 20-60 mm compr., $3 \mathrm{~mm}$ larg., creme, na frutificação (20-) 40-105 mm compr., 4-5 mm larg., verdes a marrons, retas, eretas; pedúnculos $5-15 \mathrm{~mm}$, retos, glabros ou com tricomas esparsos; bráctea floral ca. 0,5 mm, triangulares, ovais a elípticas, fortemente ciliadas; raquis glabras. Flores com 4 estames, estigmas 3, sésseis. Drupas 0,75-1,5 mm compr., 1-2 mm larg., oboval-depressas, glabras, ápice truncado.

$M$ aterial examinado: Delfinópolis, trilha para cachoeira do Alpinista, $20^{\circ} 26^{\prime} 04^{\prime \prime} \mathrm{S}, 46^{\circ} 38^{\prime} 73^{\prime \prime} \mathrm{W}, 16 . \mathrm{V} .2003$ (fl), R. Romero et al. 6899 (HUFU).

Piper arboreum ocorre do Paraguai ao M éxico e nas Índias Ocidentais (Yuncker 1973, Tebbs 1989). A subespécie é encontrada em matas de galeria e é caracterizada por apresentar o pecíolo alado com prolongamento em direção a lâmina foliar.

\subsection{Piper caldense C.DC., Linnaea 37: 343. 1872.}

Fig. 2 i-j.

Subarbustos 1-3 m alt.; ramos glabros, cobertos por glândulas castanho-claras. Profilos persistentes no ápice dos ramos, 12-25 mm compr., reflexos, glabros. Folhas membranáceas, translúcido-pontuadas, discolores, eucamptódromas; pecíolos 20-25mm, bainha alada; lâminas 15-22 cm compr., 7-8,5 cm larg., lanceoladas a elípticas, glândulas castanhas em ambas as faces; ápice agudo, base assimétrica, aguda a cuneada, diferença 8-10 mm entre os lados, margem glabra; nervuras 8-9 de cada lado, a maioria concentrada abaixo de 1/3 da lâmina foliar. Espigas 25-35 mm compr., 3-6 mm larg., na frutificação $25-36$ mm compr., 6-8 mm larg., retas, pêndulas; pedúnculos 1,5-1,8mm, curvos, glabros, poucas glândulas; bráctea floral ca. 0,5mm, orbiculares a triangulares, fortemente ciliadas, glândulas presentes ou não na porção central; raquis glabras. Flores com 4 estames, anteras com glândulas castanhas no conectivo; estigmas 3, sésseis. Drupas 1,5-3,0 mm compr.,
1-2 mm larg., obovais, base quadrangular, ápice agudo, às vezes com glândulas próximas aos estigmas, estiletes não persistentes.

M aterial examinado: São Roque de M inas, Córrego Fumal/C anteiros, 23.IX.2001 (fr), R. Romero 6185 (HUFU); PARNA Serra da Canastra, Nascente do Córrego do B árbaro, 24.VIII.1997 (fl), J.N. Nakajima et al. 2786 (HUFU); trilha da parte de baixo da cachoeira Casca D'A nta, 29.IX.1995 (fl, fr), J.N. Nakajima et al. 1440 (HUFU).

Piper caldense ocorre no N ordeste, Sudeste, Sul do Brasil (Yuncker 1972), e nos estados de G oiás e Distrito Federal (Carvalho-Silva \& Cavalcanti 2002). Os profilos reflexos, as folhas cobertas por glândulas e as espigas pêndulas caracterizam facilmente a espécie.

2.3. Piper canastrense E.F. Guim. \& M. Carvalho-Silva, B radea 10(2): 81-84. 2005.

Fig. 3 a-g.

A rbustos até $2 \mathrm{~m}$ alt.; ramos pubescentes, tricomas simples, retrorsos ou estrelados. Profilos caducos, ca. $10 \mathrm{~mm}$, ovado-lanceolados, vilosos. Folhas membranáceas, eucamptódromo-broquidódromas; pecíolos 1-2 (-4) mm, pubescentes a tomentosos, bainha basal curta; lâminas $13,5-18 \mathrm{~cm}$ compr., 2,8-4,3 cm larg., lanceoladas ou lanceolado-elípticas, levemente discolores, tricomas simples, translúcidopontuadas, face adaxial escabra, tricomas esparsos, simples, híspido-lepidotos; ápice acuminado, base assimétrica, agu$\mathrm{da}$, diferença $1 \mathrm{~mm}$ entre os lados, margem levemente revoluta; face abaxial, tricomas esparsos, simples, tricomas estrelados esparsos próximo às margens; nervuras 5- 6 de cada lado, maioria surgindo abaixo de 1/3 da lâmina foliar, nervura central na face adaxial com tricomas simples, esparsos, na face abaxial tricomas simples, patentes e tricomas estrelados esparsos. Espigas 80-85 mm compr., 2-2,5 mm larg., curvas; pedúncul os 13-15 mm, eretos, hirsutos; bráctea floral 0,4-0,6 $\mathrm{mm}$ peltada, elíptica a subtriangular, profusamente ciliadas, pedúnculo piloso; raquis glabra. Flores com 4 estames, 3 estigmas. Drupas 0,9-1 mm compr., 0,9-1 mm larg., arredondada ou oblonga, ápice côncavo, truncado, esparso-piloso, estigmas inclusos na cavidade.

$M$ aterial examinado: São R oque de M inas, $20^{\circ} 10^{\prime} 7^{\prime \prime} \mathrm{S}, 46^{\circ} 39^{\prime} 52^{\prime \prime} \mathrm{W}$, 13.VII.1997 (fl, fr), J. A. Lombardi 1832 (BHCB, RB).

Os indivíduos de P. canastrense são facilmente identificados pelas folhas lanceoladas e pela presença de tricomas simples e estrelados na face abaxial. O corre em capão de mata em meio a campo limpo, em altitudes de 1396 m, florescendo e frutificando em julho. 


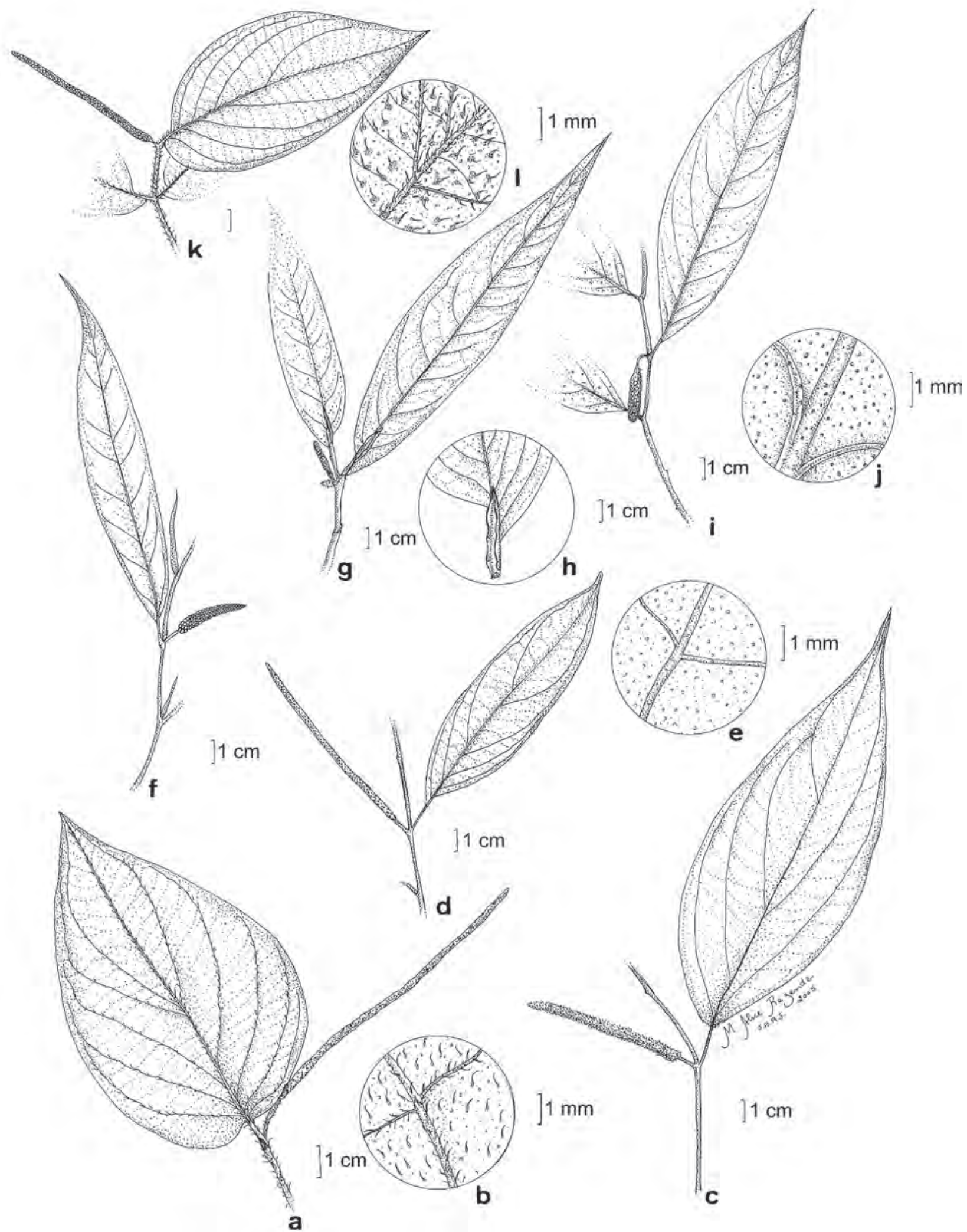

Fig. 2: a-b. Piper tectoniifolium Kunth. a-Folha e espiga, b-detal he da face adaxial da folha. c. Piper crassinervium H.B.K. d-e. Piper glabratum K unth d-folha e espiga, e-detal he da face adaxial da folha, f. Piper viminifolium Trel. g-h. Piper arboreum A ubl. g- hábito, h- detalhe do pecíolo alado. i-j. Piper caldense C.DC. i- folha e espiga, j- detal he da face adaxial da folha, k-I. Piper hispidum Sw. k- folha e espiga, I-detalhe da face adaxial da folha. 


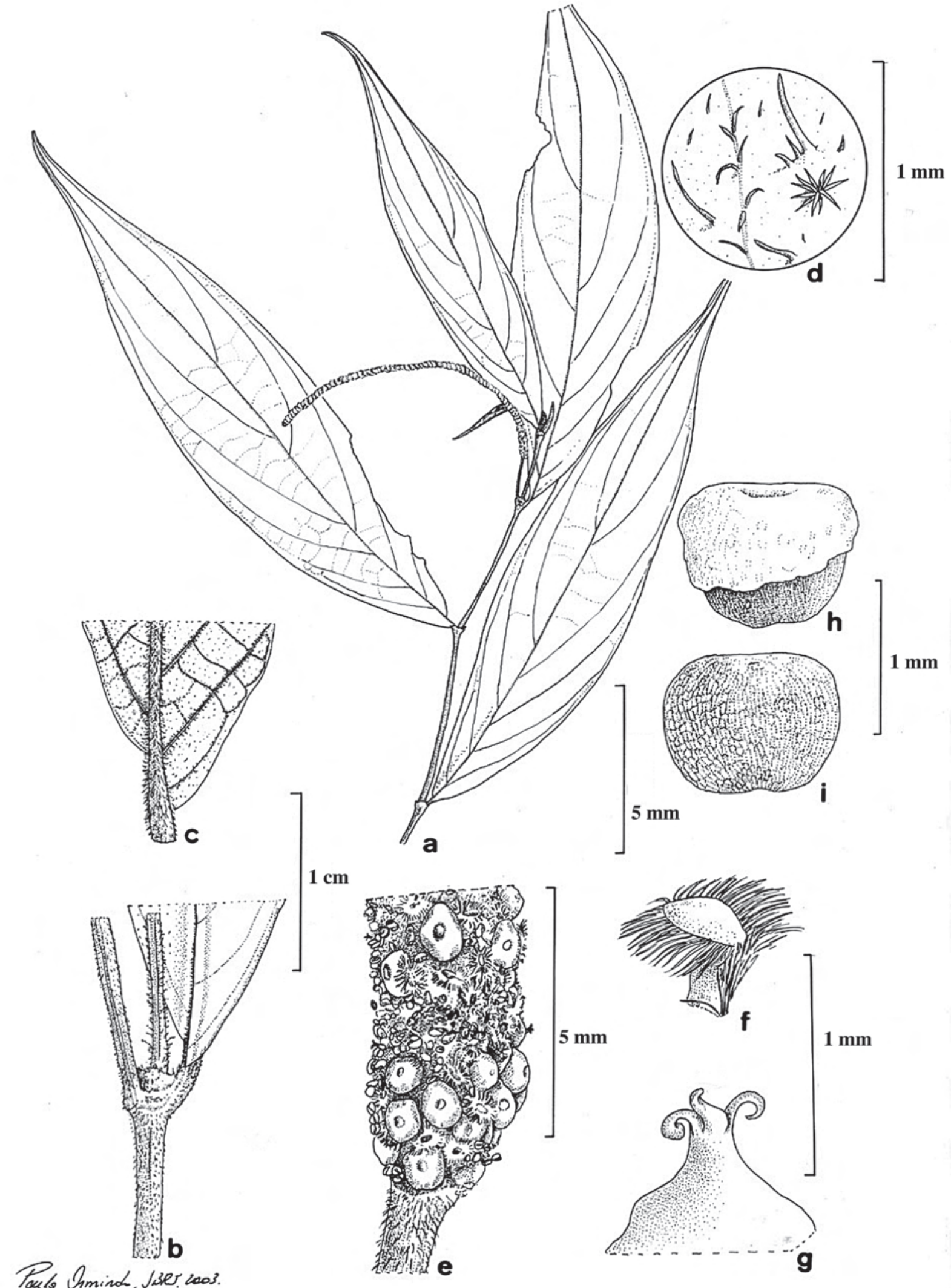

Fig. 3: a-g. Piper canastrensis E.F. Guim. \& M Carvalho-Silva. a- hábito; b - indumento do caule e pecíolo; c - detal he da base assimétrica da folha; $d$ - detalhe da face abaxial da folha evidenciando tricomas simples e estrelados; e - detal he da espiga; f - bractéola; $g$ - detal he do estigma; $h$ - drupa; i - semente. 
2.4. Piper crassinervium Kunth in H.B.K., N ov. gen. sp. pl. 1: 48. 1815.

Fig. 2 c.

A rbustos a arvoretas $2 \mathrm{~m}$ alt.; ramos glabros a levemente pubescente. Profilos caducos. Folhas cartáceas, eucamptódromas; pecíolo 10-15 mm, canaliculado; lâminas $15-20 \mathrm{~cm}$ compr., 6,5-7 cm larg., ovais a oval-elipticas; ápice agudo a acuminado, base simétrica, obtusa; glabra em ambos os lados, podendo ocorrer raros tricomas ao longo das nervuras; nervuras 3-4 de cada lado, surgindo abaixo do meio da lâmina. Espigas 7-10 cm compr., $3 \mathrm{~mm}$ larg., creme, retas, eretas; pedúnculos 8-10 mm, retos, glabros; bráctea floral ca. $0,5 \mathrm{~mm}$, ovais a elípticas, fortemente ciliadas; raquis glabra. Flores com 4 estames, estigmas 3, estilete $0,5 \mathrm{~mm}$. D rupas 0,75-1,5 mm compr., 1-2 mm larg., oboval, ápice agudo, estilete persistente, glabros.

Material examinado: São Roque de Minas, PARNA Serra da Canastra, Cachoeira Casca D'A nta, trilha para guarita de baixo, 12.V.1995 (fl), J.N.Nakajima et al. 1090 (HUFU).

Piper crassinervium são arbustos a arvoretas com fol has de base simétrica com 3-4 nervuras surgindo abaixo do meio da lâmina foliar. É diferenciada pela presença de estilete persistente no fruto. A espécie é comum no Sul, Sudeste e Centro-O este do Brasil.

2.5. Piper glabratum Kunth, L innaea 13: 633. 1839.

Fig. 2 d-e.

A rbustos 1,3 m alt.; ramos glabros. Profilos caducos. FoIhas cartáceas a membranáceas, eucamptódromas; pecíolos 6-8 mm, glabros; lâminas $12-16$ cm compr., 4-6,5 cm larg., elípticas a oval-elípticas, ápice agudo, base assimétrica, obtusa a aguda, diferença 2-3 mm entre os lados, geralmente lado menor agudo, lado maior obtuso; glabras; face abaxial com glândulas castanho-alaranjadas; nervuras secundárias 4-5 de cada lado, geralmente 3 saindo próximo a base e um par acima próximo ao centro da lâmina foliar, proeminentes; nervura principal abaxial com raros tricomas curtos e esparsos. Espigas 70-100 mm compr., $3 \mathrm{~mm}$ larg., na frutificação 80-130 mm compr., 3-4 mm larg., retas; pedúnculos 10-22 mm, eretos, glabros; bráctea floral $0,4 \mathrm{~mm}$, triangular, levemente ciliada; raquis glabra. Flores com 4 estames, estigmas 3, sésseis. Drupas 1-1,5 mm compr., 1-1,5 mm larg., obovais, glabras, ápice truncado, elíptico a oblongo, estiletes não persistentes.

Material examinado: São Roque de Minas, PARNA Serra da Canastra, Trilha da Cachoeira Casca D'A nta, mata de encosta ao longo do rio São Francisco, 20.IV.1997 (fl, fr), J.N.Nakajima et al. 2432 (CEN, HUFU); trilha da parte de baixo da Cachoeira Casca D'A nta, 29.IX 1995 (fr), J.N. Nakajima et al. 1440 (HUFU).

Piper glabratum é citada para estados de Goiás, Paraíba e São Paulo (Yuncker 1972) e Distrito Federal (CarvalhoSilva \& Cavalcanti 2002). Piper glabratum é caracterizada por apresentar folhas com a face abaxial coberta por glândulas castanho-alaranjadas, além de espigas longas e eretas. $\mathrm{Na}$ maioria das vezes, exemplares das espécie é encontrada identificada como P. caldense, devido a quantidade de glândulas castanhas nas folhas. As espécies são diferenciadas principalmente por P. caldense apresentar espigas curtas e pêndulas enquanto $P$. glabratum apresenta espigas longas e eretas.

2.6. Piper hispidum Sw., Prodr. Veg. Ind. Occ. 15. 1788 Fig. 2 k-l.

A rbustos 1,5-2 m alt.; ramos hirsutos. Profilos caducos. Folhas membranáceas, eucamptódromas,; pecíolo 5-10 mm; lâminas 9-18 cm compr., 4-8 cm larg., oval-elípticas a elípticas; ápice agudo a acuminado, base assimétrica, obtusa a levemente aguda, diferença ca. $2 \mathrm{~mm}$ entre os lados; fortemente escabras, discolores, híspidas a estrigosas; nervuras 4-5 de cada lado, saindo abaixo da metade da lâmina foliar. Espigas 75-100 mm compr., $3 \mathrm{~mm}$ larg., creme, na frutificação 90-115 mm compr., $4 \mathrm{~mm}$ larg., creme, retas, patentes a eretas; pedúnculos 6-13 mm, retos; bráctea floral ca. 0,4-0,6 $\mathrm{mm}$, triangulares a levemente elípticas, fortemente ciliadas; raquis glabras. Flores com 4 estames; estigmas 3, sésseis. D rupas 0,85-2 mm compr., 0,6-1 mm larg., obovais a oblongas, base achatada, glândulas marrons a alaranjadas, ápice truncado, estiletes não persistentes hirtelo.

Material examinado: São Roque de M inas, PARNA Serra da Canastra, trilha da parte de baixo da cachoeira Casca D'A nta, 29.IX.1995 (fl, fr), J.N. Nakajima et al. 1443 (HUFU).

Piper hispidum ocorre nas Índias Ocidentais, A mérica Central e na A mérica do Sul (Tebbs 1993). No Brasil a espécie ocorre nos estados do A mazonas, Pará, Bahia, Goiás, Ceará, M ato Grosso, Rio de J aneiro, Santa Catarina (Y uncker 1972) e Distrito Federal (Carvalho-Silva \& Cavalcanti 2002). A s fol has escabras, estrigosas e híspidas associadas a presença de glândulas no fruto caracterizam a espécie.

2.7. Piper tectoniifolium K unth, L innaea 13: 661. 1839.

Fig. 2 a-b.

A rbustos $2 \mathrm{~m}$ alt.; ramos pubescentes. Profilos caducos. Fol has membranáceas, eucamptódromas; pecíolo $20 \mathrm{~mm}$, canaliculado; lâminas 18-25 cm compr., 9-14 cm larg., ovais; ápice agudo a atenuado, base assimétrica, obtusa, diferença 2-3 mm entre os lados; pubescente a tomentosa em ambas as faces, glândulas translúcidas; nervuras 5- 6 de cada lado, surgindo abaixo do meio da lâmina, pubescentes. Espigas 18-20 $\mathrm{cm}$ compr., $3 \mathrm{~mm}$ larg., marrons, retas, eretas; pedúnculos 25-35 mm, retos, tomentosos; bráctea floral ca. 0,5 mm, elíptica, a obtusa, fortemente ciliada; raquis glabra. Flores com 4 estames, estigmas 3, sésseis. Drupas 0,75-1,5 mm compr., 1-2 mm larg., oboval-oblongo, ápice truncado, estiletes não persistentes, pubescente. 
Material examinado: D elfinópolis, cachoeira do A Ipinista, Paraíso Selvagem, $20^{\circ} 26^{\prime} 04^{\prime \prime} S, 46^{\circ} 38^{\prime} 72$ W, 13.IV.2002 (fr), R.L. Volpi et al. 156 (HUFU); estrada para "Escada de Pedras", vão na Faz. Do J osé O nório, 20²6'04"S, 46³8'72"W, 29.XI.2003 (fr), J.N. Nakajima et al. 3788 (HUFU); trilha para cachoeira do Alpinista, 20²6'04"S, 46³8'72"W, 22.X.2003 (fl), J.N. Nakajima et al. 3583 (HUFU); Paraíso Selvagem, trilha para cachoeira do Alpinista, $20^{\circ} 26^{\prime} 04^{\prime \prime} S$, 46³8' 72"W, 27.XI.2003 (fl), R. L. Volpi et al. 789 (HUFU); São Roque de M inas, PAR NA Serra da Canastra, Guarita 3, Cachoeira Casca D'A nta, 21.III.1995 (fr), R. Romero et al. 2069 (HUFU); trilha da M ata da parte de baixo da Cachoeira da Casca D'Anta, 21.II.1997 (fl), R. Romero et al. 3948 (HUFU)

Piper tectoniifolium é facilmente reconhecido pelas foIhas ovais largas e espigas longas. 0 corre em matas no Centro-O este e Sudeste do país.

2.8 Piper viminifolium Trel., Publs Field Mus. Nat. Hist. Bot. ser. 22: 12. 1940.

Fig. $2 \mathrm{f}$.

Subarbustos a arbustos 0,6-1 m alt.; ramos glabros e estriados. Profilos persistentes, $(0,5) 0,8-1,5 \mathrm{~cm}$. Fol has eucamptódromas; pecíolo 0,5-1,5 mm; lâminas 9-15 cm compr., 1,5-3,5 cm larg., oblongo-lanceoladas, glabras; ápice acuminado, base simétrica, acuminada; nervuras 6 de cada lado, a mais próxima à base prolongando-se em direção ao ápice. Espigas 20-40 mm compr., $2 \mathrm{~mm}$ larg., na frutificação 32-50 mm compr., 3-4 mm larg., eretas; pedúnculos 1-15 mm, eretos; bráctea floral ca. 0,4 mm, falciforme, glabra, raquis glabra. Flores com 3 estames, estigmas 3, sésseis. Drupas $1 \mathrm{~mm}$ compr., 0,5 mm larg., obovais, ápice levemente triangular a cônico, estiletes não persistentes, glabros.

M aterial examinado: São R oque deM inas, faz. Peroba, $46^{\circ} 19^{\prime} 49^{\prime \prime} \mathrm{W}$ $20^{\circ} 07^{\prime} 34^{\prime \prime}$ S, 25.1.2002 (fr), R. Romero 6212 (CEN, HUFU)

Piper viminifolium é caracterizada por possuir os ramos, folhas e as brácteas florais glabras. A espécie tem sido registrada apenas para $M$ inas G erais. A espécie ocor- re em matas de galeria e floresce e frutifica de agosto a fevereiro.

\section{R eferências}

CARVALHO-SILVA, M. \& CAVA LCANTI, T.B. 2002. Piperaceae In T.B. Cavalcanti \& A.E. Ramos (eds.) Flora do Distrito Federal, Brasil. Embrapa Recursos Genéticos e Biotecnologia. Brasília, vol. 2, p. 93-124.

DE CANDOLLE, C. 1869. Piperaceae. In C. De Candolle (ed.) Prodromus systematis naturalis regni vegetabilis. Crapelet. Paris, vol. 16(1), p. 235-471.

GUIM ARA ES, E.F. \& COSTA, L.H.P da. 1980. N otas em PiperaceaeV- Novos sinônimos. Rodriguésia 31(27): 149-153.

GUIMARÃES, E.F. \& GIORDANO, L.C.S. 2004. Piperaceae do N ordeste B rasileiro 1: estado do Ceará. Rodriguesia 55(86): 21-46.

GUIM A RÃ ES, E.F. 1994a. Piperaceae O rganensis. Arq. J ard. Bot. Rio de J aneiro 32: 50-106.

GUIM ARÃ ES, E.F. 1994b. Piperaceae. In M.P.M. Lima\& R.R. Guedes-Bruni (orgs.). Reserva Ecológica de Macaé de Cima. Nova Friburgo-RJ. Aspectos florístico das espécies vasculares. Jardim B otânico do Rio de J aneiro. Rio de J aneiro, p. 327-348.

GUIM A RÃ ES, E.F. 1997. Piperaceae. In M .C.M. M arques \& A.S.F.V.R $M$ arquete (orgs.). Flórula da APA Cairuçu, Parati, RJ : espécies vasculares. J ardim Botânico do Rio de Janeiro. Rio de Janeiro, p. 396-439.

GUIM ARÃ ES, E.F. \& CA RVALHO-SILVA, M. 2005. Notas em Piperaceae V III - Piper canastrense E.F. Guim. \& M. Carvalho-Silva, (Piperaceae). Nova espécie para o B rasil. Bradea 10(2): 81-84.

GUIM ARÃES, E.F., COSTA, C.G., ICHASO, C.L.F., 1977. Ottonia peltata (Piperaceae) - uma nova espécie do estado do Espírito Santo. Arq. J ard. Bot. Rio de J aneiro 20(55): 7-14.

GUIMARAES, E.F.; CA RVA LHO-SILVA, M \& \& CAVALCANTI, T.B. 2007. Piperaceae. In Flora dos Estados de G oiás e Tocantins. Coleção Rizzo. Universidade Federal de Goiás. Goiânia, vol. 32, p. 1-68.

MIQUEL, F.A.W. 1843-1844. Systema Piperacearum. K ramer. Roterdam.

MIQUEL, F.A.W. 1852. Piperaceae. In C.F.F. M artius (ed.). Flora brasiliensis. Frid. Fleischer. Leipzig, vol. 4, pars 1, p. 1-76.

TEBBS, M.C. 1989. Revision of Piper (Piperaceae) in the New World. 1. Review of characters and taxonomy of Piper section Macrostachys. Bull. Nat. Hist. 19: 117-158.

TEBBS, M.C. 1993. Revision of Piper (Piperaceae) in the New World. 3. The taxonomy of Piper section Lephianthes and Radula. Bull. Nat. Hist. 23(1): 1-50.

TRELEA SE, W. \& Y UNCKER, T.G. 1950. The Piperaceae of N orthern South A merica. U rbana 1-2: 1-837.

Y UNCKER, T.G. 1972.The Piperaceae of Brazil. I. Piper-Group I, II, III, IV. H oehnea 2: 19-366.

Y UNCKER, T.G. 1973. The Piperaceae of Brazil. II. Piper-Group V; Ottonia; Pothomorphe; Sarcorhachis. H oehnea 3: 29-284.

Y UNCKER, T.G. 1974.The Piperaceae of Brazil-III: Peperomia; Taxa of uncertain status. Hoehnea 4: 71-413. 